\title{
Simultaneous determination of some illegal antihypertensive and diuretic drugs in traditional herbal preparations by HPLC-DAD
}

\author{
Pham Van Hung ${ }^{1^{*}}$, Tran Cao Son ${ }^{2}$, Nguyen Thi Kieu Anh ${ }^{3}$ \\ ${ }^{1}$ Yen Bai Drug, Cosmetics and Food Quality Control Center, Yen Bai, Vietnam \\ ${ }^{2}$ National Institute for Food Control, Hanoi, Vietnam \\ ${ }^{3}$ Hanoi University of Pharmacy, Hanoi, Vietnam
}

(Received: 06/03/2021; Accepted: 27/04/2021)

\section{Abstract}

A simple, stable, and specific high-performance liquid chromatography coupled with a DAD detector (HPLC-DAD) method has been developed and validated for the simultaneous determination of amlodipine, felodipine, furosemide, nifedipine, and spironolactone in traditional herbal products. The analytes were extracted in acetonitrile: water $(50: 50, \mathrm{v} / \mathrm{v})$ with help of the ultrasonic. The separation of analytes was performed in an Apollo C18 column (250 $\times 4.6 \mathrm{~mm} ; 5 \mu \mathrm{m}$ ) and a mobile phase consisting of mixture acetonitrile: $0.1 \%$ phosphoric acid in gradient elution. The analyzed drugs were detected at $238 \mathrm{~nm}$. The method was validated according to the AOAC International guidelines concerning specificity, linearity, precision (repeatability, intermediate precision), accuracy, limit of detection (LOD), and limit of quantification (LOQ). The method can detect the studied drugs at the concentration of 0.66 to $1.25 \mu \mathrm{g} / \mathrm{g}$ for dry samples and 0.10 to $0.24 \mu \mathrm{g} / \mathrm{mL}$ for liquid samples. The method was successfully applied in the analysis of 17 samples in the local market. No samples were found positive for the substances to be analyzed.

Keywords: amlodipine, felodipine, nifedipine, furosemide, spironolactone, traditional herbal products.

\section{INTRODUCTION}

Hypertension is a common chronic medical condition, and it is the cause of many cardiovascular complications such as cerebrovascular accidents, myocardial infarction, arrhythmia, and heart failure. In addition to the use of pharmaceutical drugs in treatment, many traditional herbal products have been used by hypertensive patients because they believe that their therapeutic effects are more sustainable and safer than chemical drugs. However, to increase the effectiveness of treatment, some manufacturers have mixed chemical drugs into herbal products. There have been several studies to detect chemical drugs mixed in antihypertensive products such as nifedipine, hydrochlorothiazide, atenolol,... [1-4].

Amlodipine, felodipine, nifedipine, furosemide, spironolactone are drugs with antihypertensive and diuretic effects commonly used in the treatment of hypertension today with many products circulating on the market, at low cost. Therefore, these drugs are likely to be illegally mixed into herbal products. When using these products, with uncontrolled doses for a long time, users may experience unwanted effects such as heart rhythm disturbances, 
electrolyte imbalance, digestive disorders,... [5]. Therefore, the detection of substances with antihypertensive and diuretic effects mixed in herbal products is an urgent matter to protect the customer's health.

This study was conducted to develop and validate a method to simultaneously detect five drugs with antihypertensive and diuretic effects including amlodipine, felodipine, nifedipine, furosemide, and spironolactone in herbal products by high-performance liquid chromatography coupled with a diode array detector (HPLC-DAD). Our study would contribute to the quality control and supervision of health products derived from medicinal herbs to treat or support the treatment of hypertension.

\section{MATERIALS AND METHODS}

\subsection{Samples}

The samples of our study consist of two forms: liquid and dry glue samples that were prepared from folk remedy for antihypertensive and diuretic treatment. The remedies usually include the main drugs that meet the principles of antihypertensive treatment according to traditional medicine such as Morinda Citrifolia (lower blood pressure); Ziziphus Mauritiana LanK (sedation); Alisma Plantago-Aquatica, Achyranthes Bidentata (diuretics), and Styphnolobium Japonicum L Schott (strengthen the vessel walls) [6]. The composition of the drugs used to prepare the research sample matrix is presented in Table 1.

Table 1. Compositions of the drug matrix

\section{Drug remedy Compositions}

Six components

remedy

\section{Lower blood}

pressure remedy
Dioscorea Batatas 16 g, Cortex moutan 12 g, Rehmannia glutinosa 32 g, Cornus Officinalis Sieb et Zuce 16g, Alisma Plantago-aquatica 12 g, Poria cocos (Schw.) Wolf-polyporaceae $12 \mathrm{~g}$.

Morinda citrifolia 20 g, Rehmannia glutinosa 20 g, Plantago major 20 g, Styphnolobium Japonicum L. Schott 10 g, Achyranthes bidentata 10 g, Alisma Plantago-Aquatica 10g, Ziziphus Mauritiana Lank 10 g.

\subsection{Equipment and chemicals}

The main equipment used in the study is the high-performance liquid chromatography system LC 1260 with DAD (Agilent, USA).

Standard materials including amlodipine besylate (AML, 100.43\%, lot QT145090516), felodipine (FEL, 99.30\%, lot WS.0107222), nifedipine (NIF, 99.68\%, lot C0319200.03) furosemide (FUR, 99.51\%, lot 0103128) were purchased from the National Institute of Drug Quality Control. Spironolactone (WS. 98.50\%) was purchased from Hanoi University of Pharmacy. Acetonitrile, ethanol, methanol (HPLC grade), kali dihydro phosphate, and acid phosphoric (analytical grade) were obtained from Merck, German. 


\subsection{Method}

\subsubsection{Optimization of the analytical method}

Sample preparation: After being homogenized, $1.0 \mathrm{~g}$ for the solid glue sample or $5.0 \mathrm{~mL}$ for the liquid glue sample was transferred into a $25 \mathrm{~mL}$ volumetric flask. A portion of $15 \mathrm{~mL}$ extraction solvent was added into the volumetric flask, then it is sonicated for 15 minutes at room temperature. After that, the extraction solvent was added up to the mark of the volumetric flask. The solution was mixed well and centrifuged at the speed of $6,000 \mathrm{rpm}$ for 10 minutes. The extraction was filtered through a $0.45 \mu \mathrm{m}$ filter. In our study, we tested four extraction solvents including acetonitrile, methanol, acetonitrile: water $(50: 50, \mathrm{v} / \mathrm{v})$, methanol: water $(50: 50, \mathrm{v} / \mathrm{v})$. The most effective solvent giving the best peak shape would be chosen as the extraction solvent.

Chromatography conditions: Based on previous studies [1, 8-9], we investigated five reversed chromatography columns including Inertsil ODS-3 (C18, $250 \times 4.6 \mathrm{~mm} ; 5 \mu \mathrm{m})$, InertSustain AQ1 $(\mathrm{C} 18,250 \times 4.6 \mathrm{~mm} ; 5 \mu \mathrm{m})$, Eclipse XBD - C18 $(250 \times 4.6 \mathrm{~mm} ; 5 \mu \mathrm{m})$, and Apollo - C18 $(250 \mathrm{~mm} \times 4.6 \mathrm{~mm}, 5 \mu \mathrm{m})$. We also tested different mobile phases and gradients to optimized the separation of five analytes.

\subsubsection{Method validation}

The method was validated according to the AOAC 2016 guidelines [7] for selectivity, linear concentration range, accuracy and repeatability, the limit of quantification, and the limit of detection.

\section{RESULTS AND DISCUSSIONS}

\subsection{Chromatography conditions}

Based on references $[1,8-9]$, we selected reversed-phase liquid chromatography with column C18 to analyze AML, FEL, NIF, FUR, and SPI in the sample. Using acetonitrile (ACN) and $0.1 \%$ phosphoric acid solution, analyze according to the gradient mode to be able to elute the analytes in the test sample in a suitable time (Figure 1).

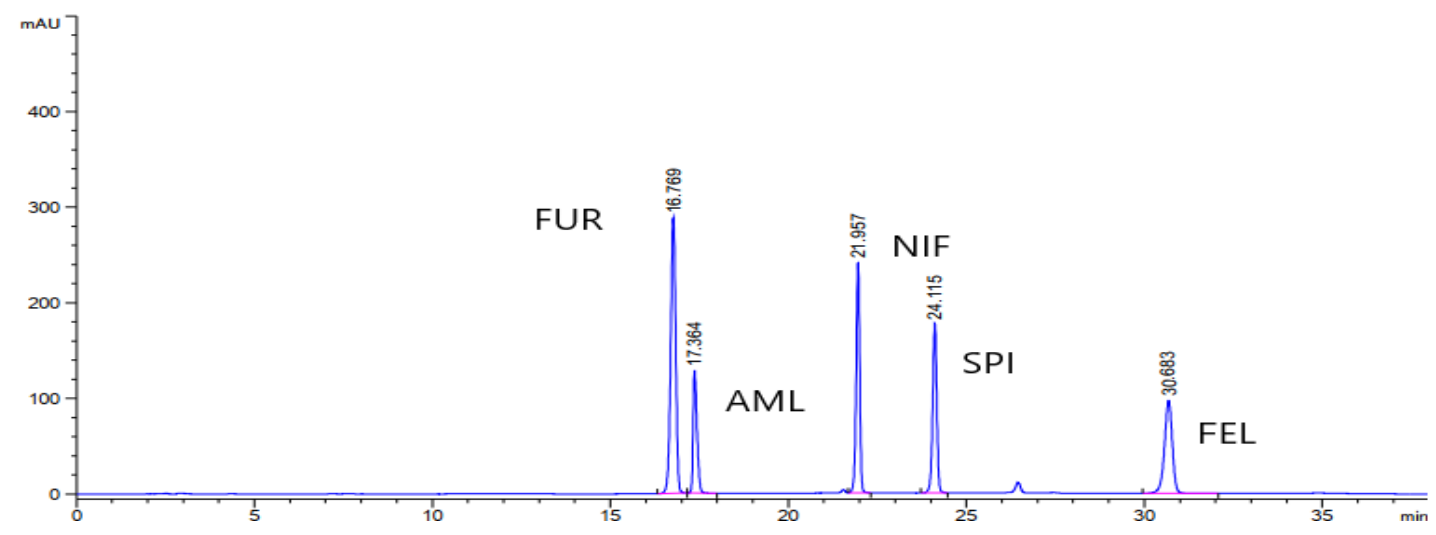

Figure 1. Chromatogram of five analytes (AML, FEL, NIF, FUR, SPI) with the mobile phases of acetonitrile and $0.01 \%$ acid phosphoric (gradient)

We carried out UV-Vis spectroscopic scanning of each research substance to determine the maximum absorption peak wavelength. The results showed that five analytes all had one absorption maximum in the range from 236 to $240 \mathrm{~nm}$. At this wavelength, the absorption 
signal is the largest. Therefore, the wavelength of $238 \mathrm{~nm}$ was selected as the wavelength for quantitative analysis.

We investigate sample injection volumes from 20 to $60 \mu \mathrm{L}$ of mixed standard solution at a concentration of $10 \mu \mathrm{g} / \mathrm{mL}$. At different injection volumes, all the peaks had compact shapes and good resolution. However, as the injection volume increased, the resolution value between the FUR and AML peaks decreased. Therefore, the study selected an injection volume of $50 \mu \mathrm{L}$ to improve the ability to detect substances in herbal products. From the obtained survey results, the analysis conditions were selected as follows:

Mobile phase A was ACN and mobile phase B was $0.1 \%$ phosphoric acid solution. The gradient program was: A - 30\% (0.0 - $10.0 \mathrm{~min})$, increase A from 30 to $60 \%$ (10.0 - $20.0 \mathrm{~min})$, A - 60\% (20.0 - $32.0 \mathrm{~min}$ ), decrease A from 60 to 30\% (32.0 - $33.0 \mathrm{~min}$ ), A - 30\% (33.0 - 38.0 $\mathrm{min})$. The chromatography column was Apolo $(4.6 \mathrm{~mm} \times 25 \mathrm{~cm} ; 5 \mu \mathrm{m})$; column temperature was set at $30^{\circ} \mathrm{C}$; flow rate was $1.0 \mathrm{~mL} / \mathrm{min}$; the injection volume was $50 \mu \mathrm{L}$; the detection wavelength was $238 \mathrm{~nm}$.

\subsection{Extraction}

Based on the solubility of substances, we have investigated the extraction solvents: methanol, acetonitrile, acetonitrile: water $(50: 50, \mathrm{v} / \mathrm{v})$, methanol: water $(50: 50, \mathrm{v} / \mathrm{v})$. The survey results showed that the two solvents acetonitrile and methanol were not suitable for the method because the peaks of the analytes are not balanced. Two extraction solvents acetonitrile: water $(50: 50, \mathrm{v} / \mathrm{v})$ and methanol: water $(50: 50, \mathrm{v} / \mathrm{v})$ both gave balanced peaks, the extraction efficiency on solid glue sample matrix was from 94.2 to $97.5 \%$; on liquid glue sample background, the solvent acetonitrile: water $(50: 50, \mathrm{v} / \mathrm{v})$ gave higher extraction efficiency. Therefore, acetonitrile: water $(50: 50, \mathrm{v} / \mathrm{v})$ was chosen as the extraction solvent. The results of the survey were shown in Figure 2.
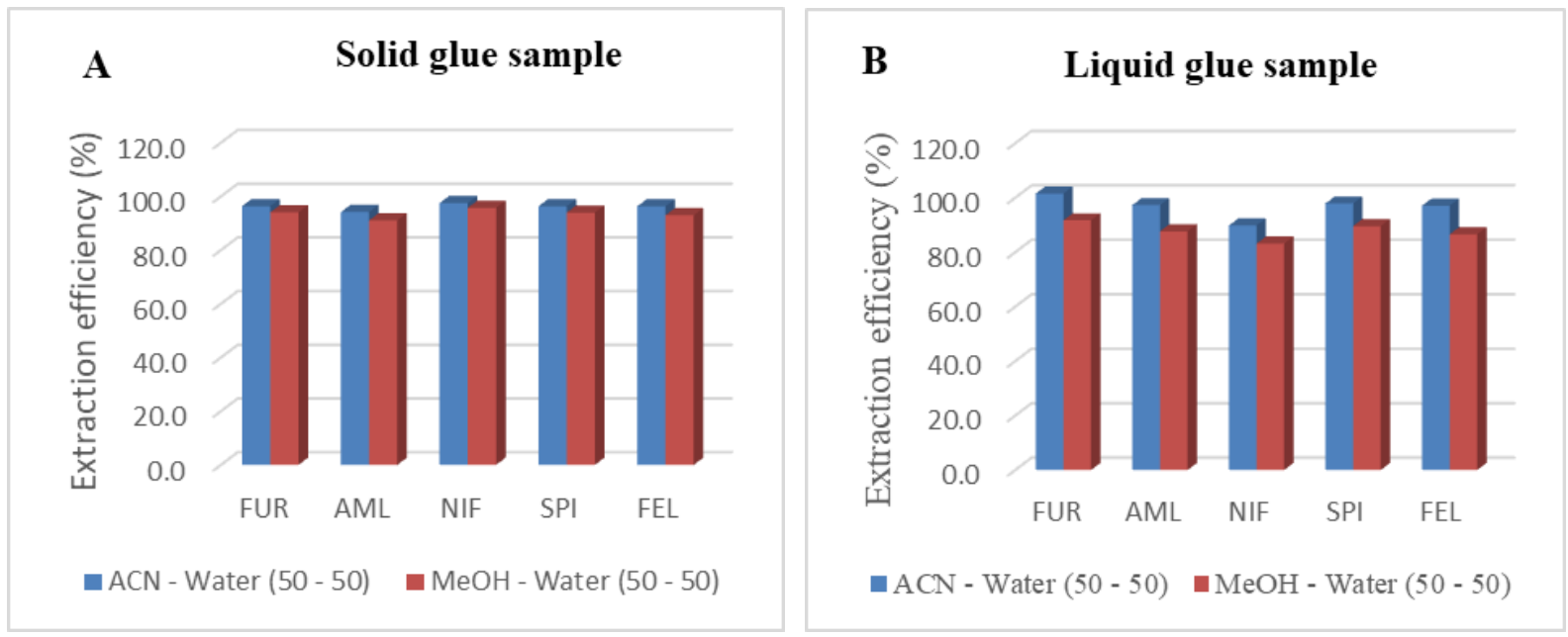

Figure 2. The extraction efficiency of acetonitrile: water (50:50, v/v) and methanol: water $(50: 50, v / v)$ in the solid $(A)$ and liquid (B) glue sample matrix

\subsection{Validation}

\subsubsection{Specificity}

We analyzed the matrix sample, the spiked sample, and the standard sample under the 
selected optimal conditions. The results showed that the chromatograms of the spiked sample appear peaks corresponding to the positions of the analytes on the chromatograms of the mixed standard solutions. On the chromatograms of the matrix samples, no peaks appeared at positions corresponding to the research substances. The spectral superposition coefficient and sample purity factor were both greater than 0.99 . Thus, the analytical method ensures specificity. Figure 3 showed the chromatogram to evaluate the specificity of the method for the liquid matrix.
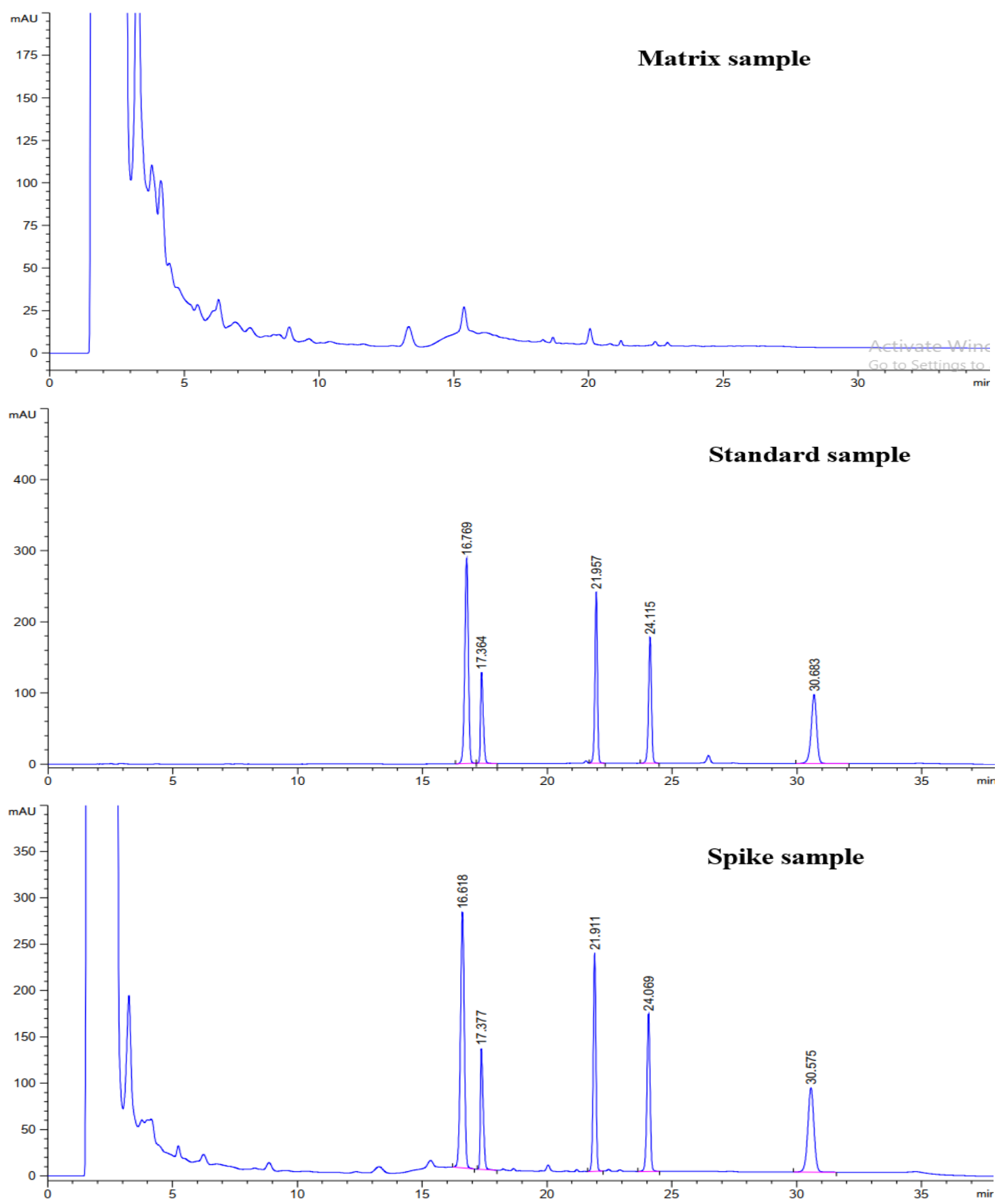

Figure 3. Chromatograms of blank matrix sample, standard sample, and spiked sample

\subsubsection{Linearity}

We analyzed mixed standard solutions of the studied substances at ten different 
concentrations and established the correlation between the peak area and the concentration of the studied substances, the results were presented in Figure 4.

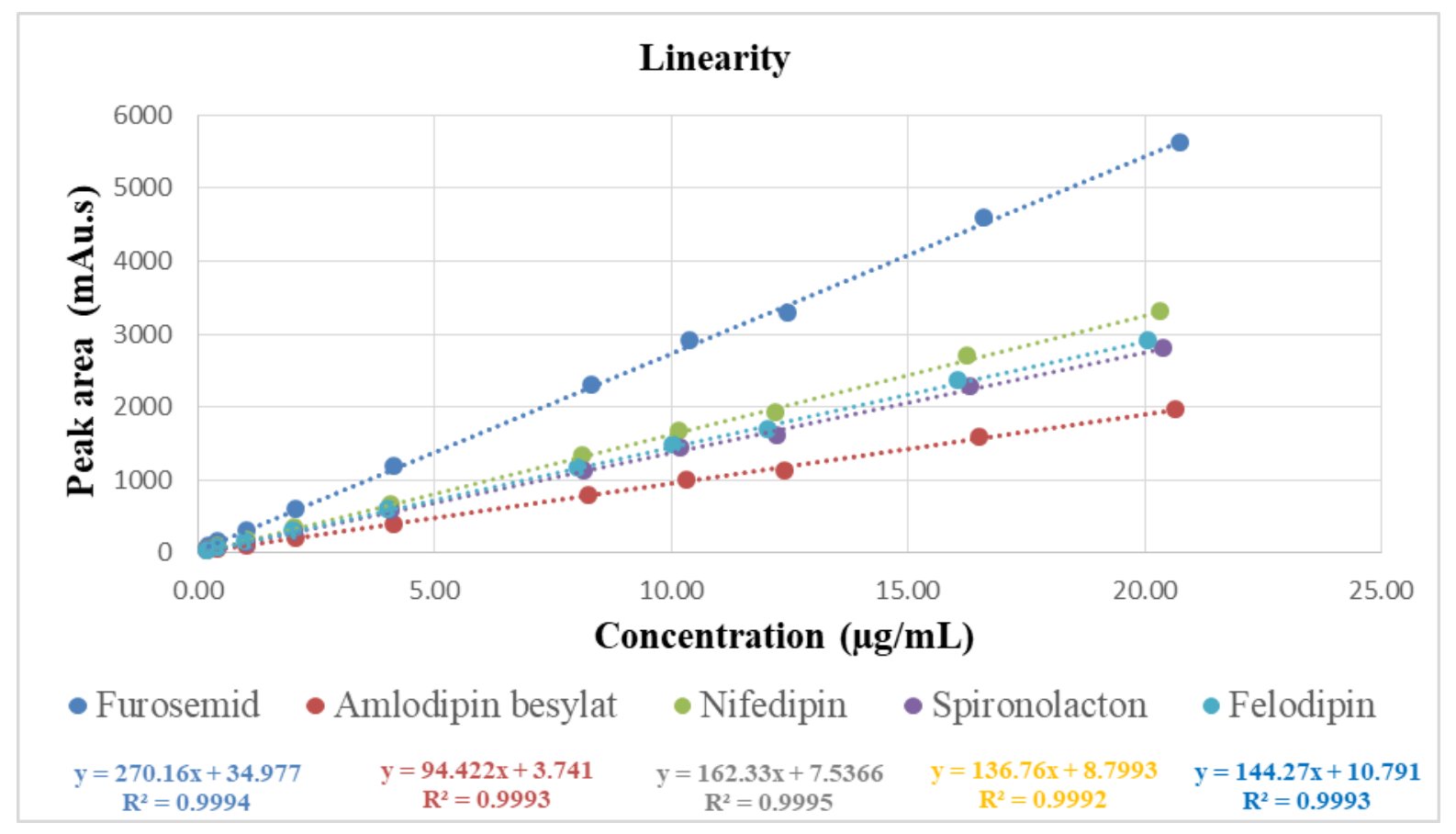

Figure 4. Calibration curves of the analytes

Figure 4 showed that in the tested concentration AML, FEL, NIF, FUR, SPI have a linear correlation between peak area and concentration, the regression coefficients of all the analytes were greater than 0.99 .

\subsubsection{Accuracy and repeatability}

The repeatability and precision were obtained by analyzing the spiked sample at three concentrations of low, medium, and high with seven replicates. Based on the peak areas of the standard addition samples (spiked sample) and the calibration curve constructed on the same day, the recovery of substances can be calculated. The repeatability was assessed through the relative standard deviation (RSD \%). The results were presented in Table 2.

Table 2. Accuracy and repeatability of the method

\begin{tabular}{|c|c|c|c|c|c|c|c|c|}
\hline \multirow{3}{*}{$\begin{array}{c}\text { Concen- } \\
\text { tration } \\
(\mu g / m L)\end{array}$} & \multicolumn{4}{|c|}{ Solid glue sample } & \multicolumn{4}{|c|}{ Liquid glue sample } \\
\hline & \multicolumn{3}{|c|}{ \% Recovery } & \multirow{2}{*}{$R S D$} & \multicolumn{3}{|c|}{ \% Recovery } & \multirow{2}{*}{$R S D$} \\
\hline & Min & Medium & $\operatorname{Max}$ & & Min & Medium & $\operatorname{Max}$ & \\
\hline \multicolumn{9}{|c|}{ Furosemide } \\
\hline 7.13 & 101.1 & 101.9 & 103.5 & 1.35 & 101.2 & 101.9 & 103.2 & 1.11 \\
\hline 11.14 & 99.1 & 102.2 & 107.9 & 3.13 & 97.8 & 101.2 & 105.4 & 3.27 \\
\hline 16.04 & 98.4 & 99.7 & 101.6 & 1.71 & 100.6 & 100.9 & 101.4 & $\mathbf{0 . 4 3}$ \\
\hline \multicolumn{9}{|c|}{ Amlodipine besylate } \\
\hline 6.88 & 101.6 & 102.3 & 103.4 & 0.95 & 102.1 & 102.6 & 103.8 & 0.95 \\
\hline 10.75 & 99.4 & 100.9 & 104.2 & 2.06 & 98.4 & 99.5 & 103.2 & 1.72 \\
\hline 15.47 & 98.3 & 99.8 & 101.8 & 1.81 & 101.9 & 102.1 & 102.6 & 0.40 \\
\hline
\end{tabular}




\begin{tabular}{ccccccccc}
\hline \multicolumn{7}{c}{ Nifedipine } \\
6.95 & 100.2 & 100.5 & 101.0 & $\mathbf{0 . 4 2}$ & 98.4 & 99.3 & 100.8 & $\mathbf{1 . 3 2}$ \\
10.87 & 98.9 & 99.3 & 100.8 & $\mathbf{0 . 8 5}$ & 96.9 & 97.9 & 98.5 & $\mathbf{0 . 6 3}$ \\
15.65 & 96.4 & 97.8 & 99.8 & $\mathbf{1 . 8 0}$ & 99.0 & 99.3 & 99.9 & $\mathbf{0 . 4 8}$ \\
\hline \multicolumn{7}{c}{ Spironolactone } \\
7.03 & 103.2 & 103.6 & 104.5 & $\mathbf{0 . 7 2}$ & 103.5 & 104.3 & 105.7 & $\mathbf{1 . 1 5}$ \\
10.99 & 99.0 & 100.4 & 101.8 & $\mathbf{0 . 9 0}$ & 97.9 & 99.1 & 100.1 & $\mathbf{0 . 7 1}$ \\
15.82 & 99.6 & 100.9 & 102.9 & $\mathbf{1 . 7 3}$ & 103.4 & 103.8 & 104.1 & $\mathbf{0 . 4 0}$ \\
\hline & & & & & & & & \\
10.72 & 98.0 & 99.4 & 100.4 & $\mathbf{0 . 8 0}$ & 97.8 & 98.5 & 99.7 & $\mathbf{0 . 6 3}$ \\
15.43 & 97.9 & 99.2 & 101.2 & $\mathbf{1 . 7 7}$ & 101.3 & 101.7 & 102.1 & $\mathbf{0 . 3 8}$ \\
\hline
\end{tabular}

It could be seen from Table 2 that for both solid and liquid glue matrix, three concentration levels, all analytes gave recoveries from $96.4-107.9 \%$, and RSD in the range of $0.42-3.27 \%$ that meet the requirement of AOAC 2016 (recovery $80-115 \%$, and RSD < 4.0\%).

\subsubsection{Limit of detection and limit of quantification}

We use the method of determining the standard deviation on a standard addition basis to evaluate the LOD. LOQ: analyze the test sample ten times according to the established procedure, calculate the mean and the standard deviation (SD). From there, calculate LOD as three times of SD and LOQ as ten times of SD. The results obtained are as follows:

Limits of detection (LOD) of the investigated substances ranged from 0.03 to $0.05 \mu \mathrm{g} / \mathrm{mL}$, equivalent to 0.66 to $1.25 \mu \mathrm{g} / \mathrm{g}$ of the dry sample and 0.10 to $0.24 \mu \mathrm{g} / \mathrm{mL}$ of the liquid sample. The limit of quantification (LOQ) ranged from 0.14 to $0.17 \mu \mathrm{g} / \mathrm{mL}$ equivalent to $2.21-4.18 \mu \mathrm{g} / \mathrm{g}$ dry sample and 0.48 to $0.80 \mu \mathrm{g} / \mathrm{mL}$ liquid sample. R values were between $5.6-9.5$ indicate LOD and LOQ were reliable.

\subsection{Analyze real sample}

This procedure was applied to analyze 17 samples of herbal products currently circulating in the local market, including four samples of tablets, six samples of capsules, two samples of a liquid solution, two samples of nuggets powder, one sample of hard pellets, and two tea bags samples. Of which, 12 samples have indications for treatment and support for high blood pressure, and five samples have liver-cooling and diuretic effects.

The results of analysis of the real samples showed that 14/17 samples did not detect peaks corresponding to the retention time of all five analytes on the chromatogram; two samples appeared a peak with the same retention time as spironolactone; one sample showed a peak with the same retention time as felodipine. We have performed UV-VIS superimposition of the suspect peaks against the standard peak. The results were illustrated in Figure 5. 

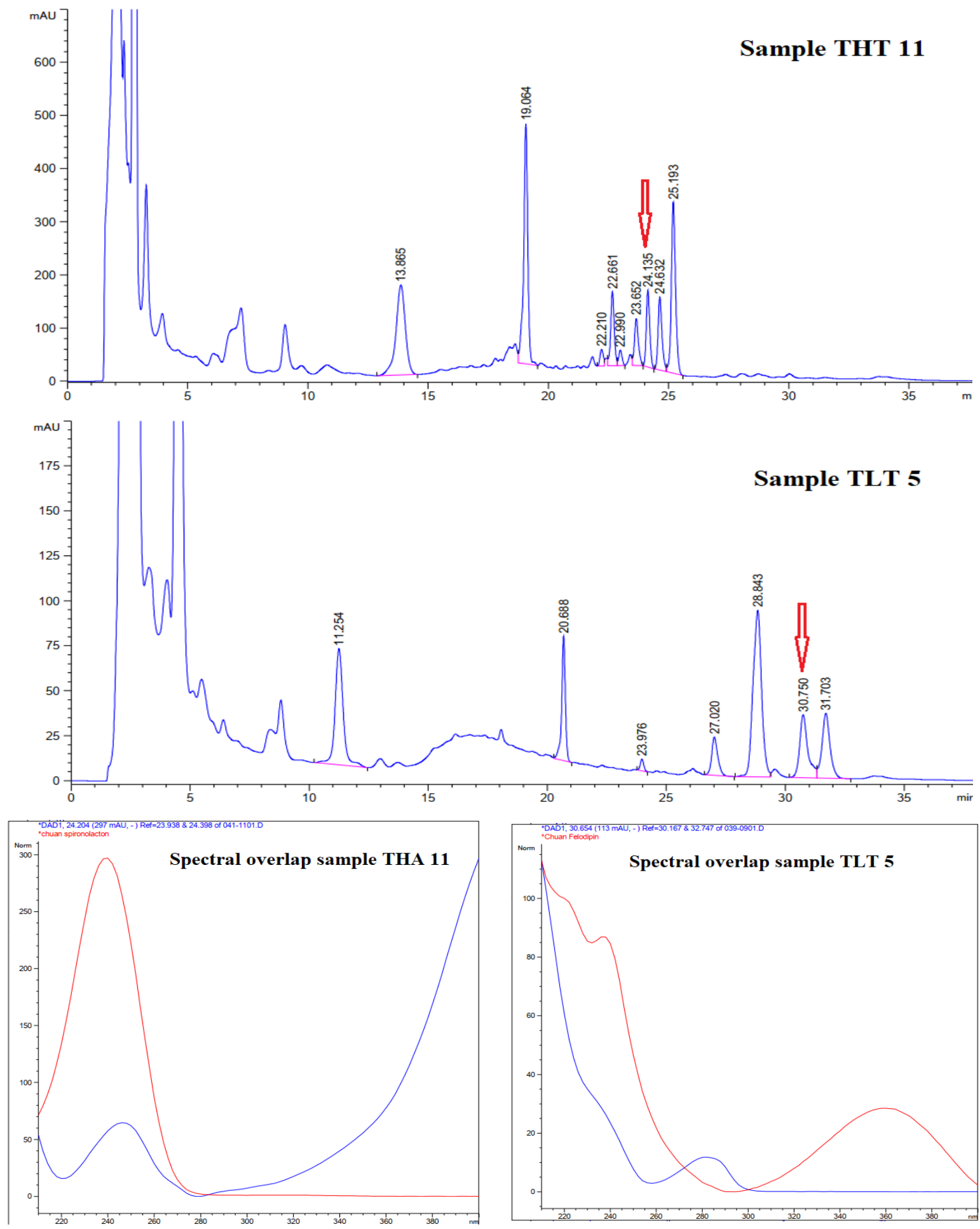

Figure 5. Chromatograms of THA11 and TLT5 sample; UV-VIS superimposition of the suspect peaks against the SPI and FEL standard peaks

The results showed that the test spectral shapes did not coincide with the standard spectral shapes. The spectral overlap coefficients were $20.28,518.37$, and 692.31 . So the suspect peaks were not the active substance under analysis. 


\section{CONCLUSION}

A method for simultaneous determination of amlodipine, felodipine, furosemide, nifedipine, and spironolactone mixed in herbal products for the treatment or support of hypertension and diuresis on solid and liquid glue samples by HPLC-DAD has been successfully developed. The method has a linear range from 0.20 to $20 \mu \mathrm{g} / \mathrm{mL}$, correlation coefficient $\mathrm{R}^{2}>0.997$; high sensitivity with LOD from 0.03 to $0.05 \mu \mathrm{g} / \mathrm{mL}$, the accuracy and precision met the requirements with the recovery from 96.4 to $107.9 \%$ and the RSD of 0.42 to $3.77 \%$. Analysis on 17 real samples showed that there was no sample containing amlodipine, felodipine, furosemide. nifedipine and spironolactone.

\section{ACKNOWLEDGMENT}

This study was supported by funding from the Ministry of Health's project "Development of a method for simultaneous analysis of some new drugs of the antihistamine and antihypertensive groups illegally mixed in herbal preparations using HPTLC, HPLC, and LC-MS/MS" period $2021-2022$.

\section{REFERENCES}

[1]. S. H. Geum, J. Y. Ji, Y. Choi, H. J. Park, S-K. Park, and S. Y. Baek, "A rapid method for the simultaneous determination of 25 anti-hypertensive compounds in dietary supplements using ultra-high-pressure liquid chromatography," Food Additive Contaminant. Part A Chemistry Analysis Control Exposure Risk Assessesment, vol. 33, no.11, pp. 1627-1636, 2016.

[2]. J. R. Kesting, J. Huang, and D. Sørensen, "Identification of adulterants in a Chinese herbal medicine by LC-HRMS and LC-MS-SPE/NMR and comparative in vivo study with standards in a hypertensive rat model," Journal of Pharmaceutical Biomedical Analysis, vol. 51, no. 3, pp. 705-711, 2010.

[3]. Y. L. Lu, N. L. Zhou, S. Y. Liao, N. Su, D. X. He, Q. Q. Tian, B. Chen, and S. Z. Yao, "Detection of adulteration of anti-hypertension dietary supplements and traditional Chinese medicines with synthetic drugs using LC/MS," Food Additive Contaminant. Part A Chemistry Analysis Control Exposure Risk Assessesment, vol. 27, no. 7, pp. 893-902, 2010.

[4]. A. P. L. Moreira, L. A. Gobo, C. Viana, and Leandro Machado de Carvalho, "Simultaneous analysis of antihypertensive drugs and diuretics as adulterants in herbal-based products by ultra-high performance liquid chromatography-electrospray tandem mass spectrometry," Analytical Methods, vol. 8, no. 8, pp. 1881-1888, 2016.

[5]. Ministry of Health, Vietnam National Pharmacopoeia. Hanoi: Medical Publisher, 2018.

[6]. Ministry of Health, Pathology and medical treatment (Combining Eastern - Western medicine). Hanoi: Medical Publisher, 2007, pp. 9-33.

[7]. AOAC International, Guidelines for Dietary Supplements and Botanicals: Appendix K, 2016.

[8]. Ministry of Health, Pharmacopoeia of Vietnam. Hanoi: Medical Publisher, 2017.

[9]. The United States Pharmacopoeia 40. 2017. 


\title{
Xác định đồng thời một số thuốc hạ huyết áp và lợi tiểu trộn trái phép trong các chế phẩm đông dược bằng HPLC-DAD
}

\author{
Phạm Văn Hùng ${ }^{1}$, Trần Cao Sơnn ${ }^{2}$, Nguyễn Thị Kiều Anh ${ }^{3}$ \\ ${ }^{1}$ Trung tâm Kiểm nghiệm Thuốc - Mỹ Phẩm - Thực Phẩm tỉnh Yên Bái, Yên Bái, Việt Nam \\ ${ }^{2}$ Viện Kiêm nghiệm an toàn vệ sinh thực phẩm Quốc gia, Hà Nội, Việt Nam \\ ${ }^{3}$ Trường Đại học Dược Hà Nội, Hà Nội, Việt Nam
}

Tóm tắt

Nghiên cứu sử dụng phương pháp HPLC kết hợp detector DAD để xác định đông thời amlodipine, felodipine, furosemide, nifedipine và spironolacton trộn trong chế phẩm có nguôn gốc thảo dược. Mẫu phân tích được chiết siêu âm trong dung môi acetonitril : nước tỷ lệ (50 : 50 , v/v) và phân tích trên cột Apollo $C 18(250 \times 4,6 \mathrm{~mm} ; 5 \mu \mathrm{m})$. pha động gồm acetonitril và acid phosphoric $0.1 \%$ theo chương trình gradient. Bước sóng phân tích là $238 \mathrm{~nm}$. Phương pháp đã được thẩm định theo hướng dẫn của $\mathrm{AOAC}$ về độ chọn lọc, khoảng tuyến tính, độ đúng, độ lặp lại, LOD và LOQ. Phương pháp có thể xác định các chất nghiên cứu ở hàm lượng từ 0,66 - 1,25 $\mu \mathrm{g} / \mathrm{g}$ đối với mẫu rắn và từ $0,10-0,24 \mu \mathrm{g} / \mathrm{mL}$ đối với mẫu lỏng. Ứng dụng quy trình đã xây dựng để xác định đồng thời amlodipine, felodipine, furosemide, nifedipine và spironolacton trong 17 mẫu đang lưu hành trên thị trường, không phát hiện mẫu nào dương tính.

Tư khóa: amlodipin, felodipin, nifedipin, furosemid, spironolacton, chế phâm đông dược, HPLC - DAD. 